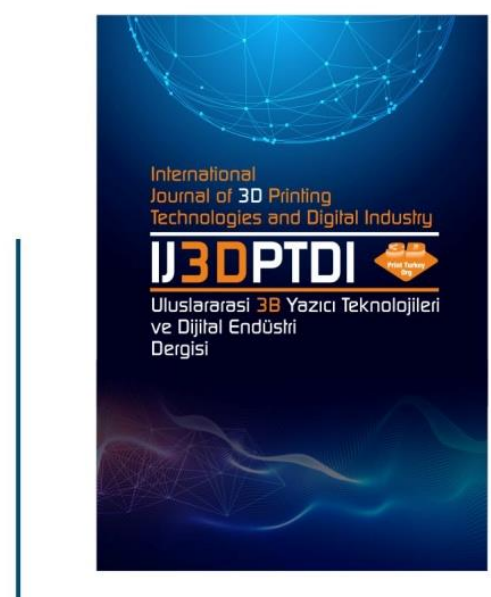

ULUSLARARASI 3B YAZICI TEKNOLOJILERI

VE DIJITAL ENDÜSTRI DERGISI

INTERNATIONAL JOURNAL OF 30 PRINTING TECHNOLOGIES AND DIGITAL INDUSTRY

ISSN:2602-3350 [Online]

URL: https://dergipark.org.tr/ij3dptdi

\title{
NUMERICAL INVESTIGATIONS AND BENCHMARKING OF THE PHYSICAL AND ELASTIC PROPERTIES OF 316L CUBIC LATTICE STRUCTURES FABRICATED BY SELECTIVE LASER MELTING
}

Yazarlar (Authors): Özgür Poyraz ${ }^{\circledR *}$, Bayram Emirhan Bilici® , Şükrü Can Gedik

Bu makaleye şu şekilde atıfta bulunabilirsiniz (To cite to this article): Poyraz Ö., Bilici B.E., Gedik Ş.C., "Numerical Investigations And Benchmarking Of The Physical And Elastic Properties Of 3161 Cubic Lattice Structures Fabricated By Selective Laser Melting" Int. J. of 3D Printing Tech. Dig. Ind., 6(1): 13-22, (2022). 


\title{
NUMERICAL INVESTIGATIONS AND BENCHMARKING OF THE PHYSICAL AND ELASTIC PROPERTIES OF 316L CUBIC LATTICE STRUCTURES FABRICATED BY SELECTIVE LASER MELTING
}

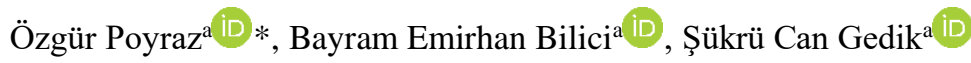 \\ ${ }^{a}$ Eskişehir Technical University, Engineering Faculty, Mechanical Engineering Department, TURKEY \\ *Corresponding Author: ozgurpoyraz@eskisehir.edu.tr
}

(Received: 08.12.2021; Revised: 04.02.2022; Accepted: 13.02.2022)

\begin{abstract}
The aim of this study is to investigate and benchmark the physical and elastic properties of strut-based lattice structures produced by selective laser melting from 316L stainless steel material, which has many uses in various sectors. Within the scope of the presented study, the relative density and relative elastic modulus for 27 types of strut-based lattice structures of different sizes with simple cubic (SC), bodycentered cubic (BCC) and face-centered cubic (FCC) geometry were evaluated and compared. Numerical analyzes were utilized due to the evaluated design and dimensional configuration diversity, and consistent results were obtained with the studies published in the previous literature. The findings of the study showed that for all lattice structure types, volume fraction increases with the increasing diameter and decreases with the increasing cell size. With the utilization of same strut diameter and cell size FCC type lattice structures exhibit the highest volumetric fill while SC type lattice structures exhibit the lowest. The increase in the volume fraction increases the relative elastic modulus. For the same volume fraction, SC lattices represent the highest relative elastic modulus while FCC lattices indicate the lowest.
\end{abstract}

Keywords: Additive Manufacturing. Selective Laser Melting. Strut-based Lattice Structures. Design. Finite Element Analysis.

\section{INTRODUCTION}

Among the different advantages offered by additive manufacturing (AM) technologies, it is remarkable that more complex designs can be realized without affecting product and production costs too much [1]. Thanks to these complex designs, different aspects of product functions can be improved. Examples of these improvements are weight reduction, customized geometries, integrated components with reduced assembly requirements, and highperformance internal channels in terms of heat and flow [2]. There are different methods of achieving weight reduction among these examples, and the two most common methods are topology optimizations and the use of lattice structures. Lattice structures are designs whose unit geometry consists of struts, shells or triply periodic minimal surfaces (TPMS), and this unit geometry repeats each other in different directions and fills the selected volume.
The first introduction of strut-based lattice structures emerged with conventional manufacturing techniques, and their application area have subsequently expanded thanks to their suitability for many different AM methods [3].

Today, among the major additive manufacturing methods grouped according to international standards, different methods such as powder bed fusion, material extrusion, material jetting and photopolymerization stand out among the ones suitable for lattice structures production [4]. Powder bed fusion additive manufacturing (PBF-AM) which covers several sub process types such as Selective Laser Melting (SLM) has the widest application area when it comes to metal alloys [5]. In order to understand the reasons for this situation, it will be useful to pay attention to the advantages of PBF-AM. In this context, the precision superiority of the PBF-AM method, which is based on the principle of laying a very thin powder layer on a build platform and melting 
and solidifying the powders in the layer with the help of a focused energy source (laser for SLM) is compelling. Moreover, the metal material variety in SLM is quite good and many alloy groups based on aluminum, cobalt, iron, nickel, steel, and titanium are appropriate for this method [1], [6], [7]. The steel grades available for SLM include but not limited to 316L,174PH, 18Ni-300, H13, PM2000 and SAF2705 [8].

Amidst the listed steel grades, 316L is an austenitic stainless steel applied by various industries including aviation, chemical and food processing, marine, power generation and environmental treatment. As the result of ongoing attempts since the beginning of early 2000 s, 316 can now successfully processed by SLM yielding to fully dense material properties. $316 \mathrm{~L}$ steel grade is also a notable research topic for the SLM production of lattice structures. For the current state-of-the-art, the types of lattice structures produced by SLM from $316 \mathrm{~L}$ are gyroid [9], face-2-centered cubic (F2CC) [10], $\mathrm{X}$-shaped [11], octet truss [12], (Z reinforced body-centered cubic) BCCZ [13], [14], cubic [15], octahedral [16], BCC [17], [18], [19] and gradient [20]. As can be seen through listed literature there are many studies on the SLM production of lattice structures from $316 \mathrm{~L}$, but there is a certain gap of a comprehensive benchmark between various lattice types and geometrical characteristics. Furthermore, the different approaches in the current literature exposes different reports and there is no compatibility between these [9]-[19]. In order to examine this situation in more detail and to understand it better, literature review was conducted and the results of different studies were observed. In the review, physical and elastic values given in some publications were used directly, while in others, physical and elastic values were extracted by making indirect calculations from different quantities such as force, area, and deformation given in the publications. Table 1 summarizes previous studies on lattice structure production with SLM using $316 \mathrm{~L}$ stainless steel.

Table 1. Previous studies on lattice structure production with SLM using 316L stainless steel.

\begin{tabular}{lcccc}
\hline $\begin{array}{l}\text { Ref. } \\
\text { No. }\end{array}$ & Scope of the Study & Data Collection Method & $\begin{array}{c}\text { Relative } \\
\text { Density (\%) }\end{array}$ & $\begin{array}{c}\text { Relative } \\
\text { Elasticity (\%) }\end{array}$ \\
\hline \hline$[9]$ & Experimental investigation & Direct retrieve from publication & 16.87 & 13.57 \\
{$[12]$} & Numerical investigation & Indirect calculation & 20 & 19.3 \\
{$[13]$} & Experimental investigation & Direct retrieve from publication & $3-14$ & $0.13-2.6$ \\
{$[16]$} & Experimental investigation & Direct retrieve from publication & 12.8 & 0.3 \\
{$[17]$} & Experimental investigation & Indirect calculation & 42 & 30.5 \\
{$[19]$} & Experimental investigation & Indirect calculation & 45.7 & $7.7-12.3$ \\
\hline
\end{tabular}

Considering the cost of the SLM process and $316 \mathrm{~L}$ stainless steel materials, it is understandable that different lattice structures and their geometric properties cannot be included in a single study by the same research group or institute. For this reason, this publication was presented to fill the gap in the literature, and the physical and elastic properties of 27 different combinations were compared in total by changing the strut diameter at 3 levels and cell size at 3 levels for each of the 3essential strut-based lattice structures.

\section{MATERIALS AND METHODS}

This paper numerically investigates and benchmarks the physical and elastic properties of $316 \mathrm{~L}$ cubic lattice structures. To fulfill this aim, simple cubic (SC), body-centered cubic (BCC) and face-centered cubic (FCC) lattice structures were designed with a commercial computer-aided design (CAD) software. After describing the geometrical characteristics, analytical models were introduced to calculate volume fraction and implemented by using MATLAB software. These analytical models were verified by calculating the volume fraction ratios with the values extracted from the CAD models of lattice structure and full cubic volumes. Later on, finite element analyses (FEA) were employed by using ANSYS software and FEA set-up was fine-tuned by verification with the experimental values taken from previous literature and mesh sensitivity analyses. Finally, full set of lattice structures 
were simulated and benchmarked in terms of physical and elastic properties.

\subsection{Design of Lattice Structures}

According to published literature, SC, BCC and FCC type lattice structures are among the common ones which employ struts and they are also called as strut-based lattice structures accordingly [21]. The so-called struts are represented as cylinders with a constant diameter and they act like bridges between the joining point of lattices. These joining points are arranged similar to atomic lattices and $\mathrm{SC}$ has its points in the corner of the cubes, while BCC and FCC have additional ones at body or face centers. Figure 1 shows 8 cubic lattices of each type with joining points, struts, diameters and other geometrical characteristics.

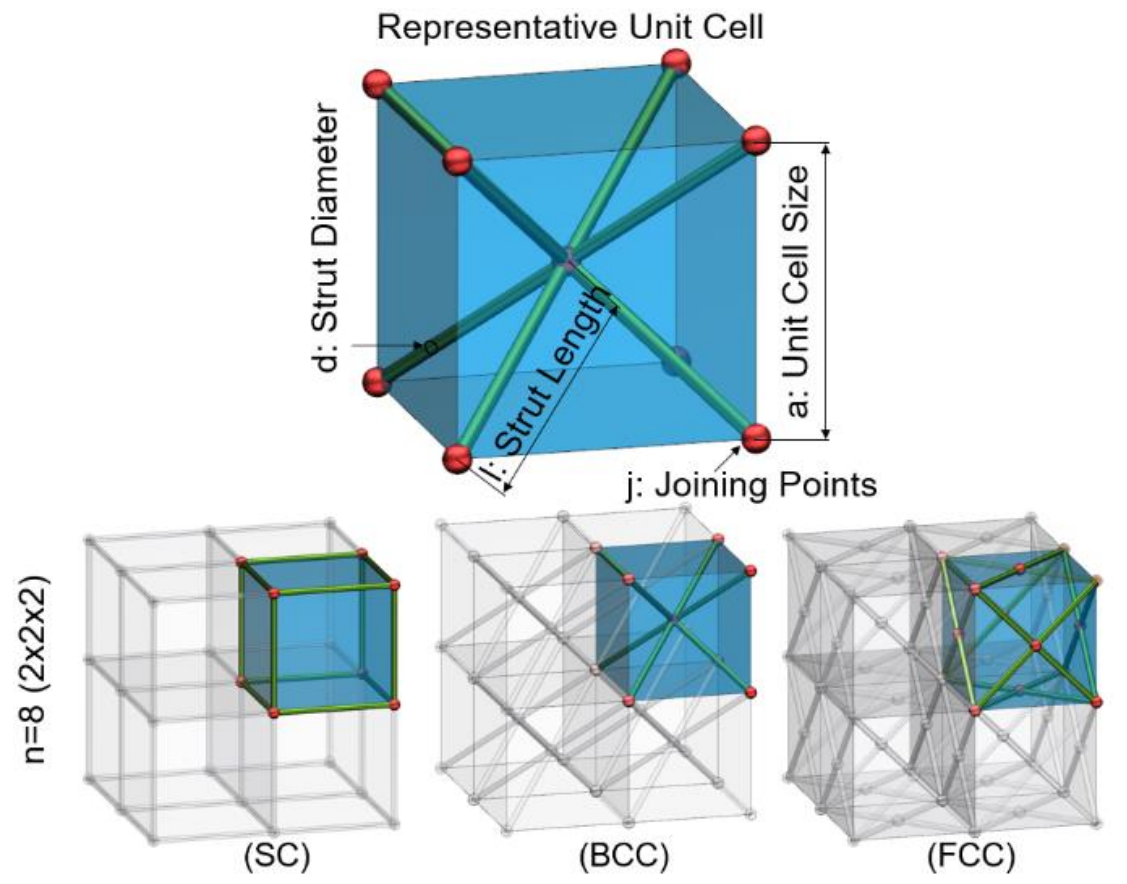

Figure 1. Cubic lattices of each type with joining points, struts, diameters and other geometrical characteristics

In the context of the current study, 3 levels were determined for strut diameters and cell dimensions. For all lattice structure types of SC, BCC and FCC, cell sizes were selected as $3 \mathrm{~mm}$, $4 \mathrm{~mm}$ and $5 \mathrm{~mm}$. Together with this, strut diameters were determined as $0.6 \mathrm{~mm}, 0.8 \mathrm{~mm}$ and $1 \mathrm{~mm}$. For the lattice structures studied in this publication, abbreviations are used to include the structure name, then the cell size, and finally the beam diameter. For example, a BCC structure with a cell size of $3 \mathrm{~mm}$ and a beam diameter of $1 \mathrm{~mm}$ is called BCC-a3-d1. Finally, it is worth emphasizing that all cubic lattices were designed with 4 cells in each of the 3 axes $(n=64(4 \times 4 \times 4))$, and there are prismatic bodies at the top and bottom of the lattice systems to represent the physical compression state.

\subsection{Analytical Modeling of Volume Fraction} After explaining the geometrical characteristics, analytical models were introduced to calculate volume fraction and implemented using
MATLAB software. In order to calculate the volume fraction, first of all, the number of struts in the unit cell (b) was considered. Accordingly, there are 10 struts in the SC type unit cell, 8 struts in the BCC type unit cell and 24 struts in the FCC type unit cell. However, when the whole lattice structure is taken into account and the adjacent cells are considered, it is seen that the unit cells of the SC and FCC type lattices share their struts with the neighboring cells. For this reason, the number of struts per unit cell of these two types should be taken as 1/4. As can be seen from Figure 1, in BCC type lattices, the unit cell does not share its struts with neighboring cells.

Subsequently, the strut lengths of the lattice structures were calculated according to the unit cell size. While the strut lengths for SC type lattice structures are the same as the unit cell size, the strut lengths of BCC type lattice structures are equal to half of the body diagonal length and FCC type lattice structure strut 
lengths are equal to half of the face diagonal length. Later on, cross sectional areas of each strut were included in the calculation according to area of circle equation.

The volume of each lattice structure type was obtained by multiplying all the aforementioned calculations with each other. However, it should be noted that the struts were calculated as full length and for certain types, the excess due to overlapping at the joining points should be subtracted from the total volume. For example, overlaps are present in the FCC type lattice structures at the joining points of 24 struts and additional volume representing them must be subtracted from the total volume.

The final equation can be derived by multiplying the overall calculations with the number of cells (n) and dividing that with the volume of full cube. Introduced models of volume fraction ratio for each lattice structure type are provided below. Equation 1 is used for $\mathrm{SC}$ type lattice structures, while Equation 2 is used for BCC and Equation 3 is used for FCC.

$$
\begin{aligned}
& \frac{100 \cdot\left(12 \cdot a \cdot \pi \cdot r^{2}-\frac{8}{3} \cdot \pi \cdot r^{3}\right)}{a^{3}} \\
& \frac{100 \cdot\left(8 \cdot a \cdot \frac{\sqrt{3}}{2} \pi \cdot r^{2}-\frac{48}{3} \cdot \pi \cdot r^{3}\right)}{a^{3}} \\
& \frac{100 \cdot\left(12 \cdot a \cdot \frac{\sqrt{2}}{2} \pi \cdot r^{2}-\frac{48}{3} \cdot \pi \cdot r^{3}\right)}{a^{3}}
\end{aligned}
$$

These analytical models were verified by calculating the volume fraction ratios with the values extracted from the CAD models of lattice structure and full cubic volumes. According to the conducted verifications, equations show good convergence with CAD models and for various configurations of $\mathrm{SC}, \mathrm{BCC}$ and $\mathrm{FCC}$ lattice structure types, and the differences between two methods are less than $2 \%$.

\subsection{Numerical Modeling}

This paper numerically investigates elastic properties of $316 \mathrm{~L}$ cubic lattice structures by employing finite element analyses (FEA) using ANSYS software. The essential physical and mechanical properties of bulk $316 \mathrm{~L}$ used for the current study were derived from ANSYS software material database, and are presented in Table 2.
The boundary conditions were defined by employing displacements at the top face of the upper prismatic body along $-\mathrm{Z}$ axis, and also applying fixed constraint at bottom face of the lower prismatic body. Figure 2 exhibits the displacement boundary condition with letter "A" and fixed constraint boundary condition with letter " $B$ ". In order to verify the FEA model with the experimental values, an up-todate scientific publication was selected as reference [17], and boundary conditions were applied accordingly. In this respect, a total of $12 \mathrm{~mm}$ displacement was determined for an interval of $12 \mathrm{~s}$ time and a force reaction probe was utilized at the fixed constraint face for monitoring reaction forces.

Table 2. Bulk 316L properties (Derived from ANSYS database)

\begin{tabular}{lcccc}
\hline \hline Property & Unit & \multicolumn{4}{c}{ Value } \\
\hline \hline $\begin{array}{l}\text { Reference } \\
\text { Temperature }\end{array}$ & ${ }^{\circ} \mathrm{C}$ & 50 & 400 & 600 \\
$\begin{array}{l}\text { Density } \\
\text { Elastic } \\
\text { Modulus } \\
\text { Poisson }\end{array}$ & $10^{-3} \mathrm{~kg} / \mathrm{m}^{3}$ & 7955 & 7840 & 7685 \\
$\begin{array}{l}\text { Ratio } \\
\text { Yield }\end{array}$ & - & 0.26 & 0.31 & 0.32 \\
$\begin{array}{l}\text { Strength } \\
\text { Ultimate }\end{array}$ & $10^{8} \mathrm{~Pa}$ & 2.43 & 1.65 & 1.25 \\
$\begin{array}{l}\text { Tensile } \\
\text { Strength }\end{array}$ & $10^{8} \mathrm{~Pa}$ & 5.65 (constant) \\
\hline
\end{tabular}

Different mesh types and variable mesh sizes were applied for upper/lower prismatic bodies and $\mathrm{BCC}$ type lattice structure. 3D hexahedral elements with 20 nodes (Hex20) were used for upper/lower prismatic bodies since the geometries of prismatic bodies were suitable for the adoption of Hex20 mesh type. Gradient mesh element sizes were defined for Hex20 elements starting with a minimum of $1.5 \mathrm{~mm}$ and ending up to a maximum of $4 \mathrm{~mm}$. Contrarily, quadratic tetrahedral elements with 10 nodes (Tet10) were used for the lattice structures. This is because lattice structures consist of intersecting struts and Tet10 mesh element is a better geometrical fit to lattice structures than Hex20. In the selection of the dimensions of the Tet 10 elements, attention was paid to ensure that the element dimensions were smaller than $1 / 8$ of the strut diameter, and thus, an acceptable level of geometrical convergence 
to the circular cross section of the beams was achieved. Mesh metric statistics were also used to verify the quality of the elements and high quality with reasonable aspect ratios were obtained in more than $95 \%$ of the elements.

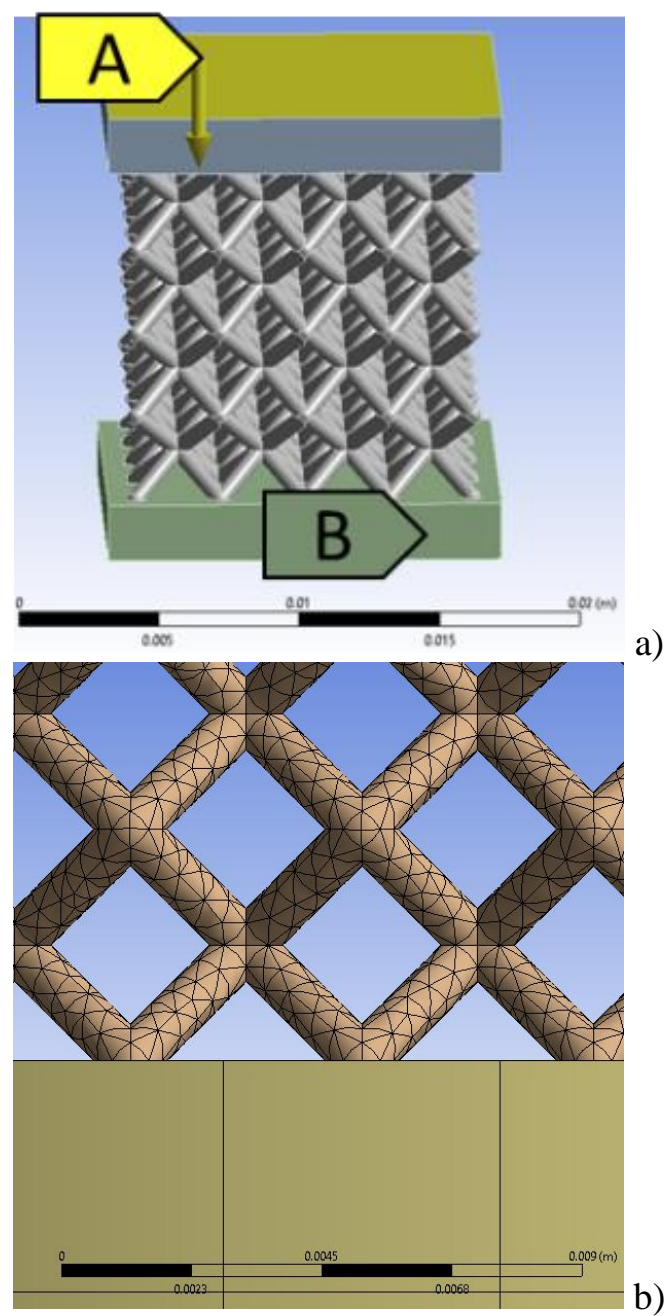

Figure 2. a) Displacement (A) and fixed constraint (B) boundary conditions, b) Close-up view of mesh elements.

After the mesh element type was determined and the initial dimensions were selected, mesh element sensitivity analyzes were performed to confirm the reliability of the model. In order to carry out this verification, lattice structures with a cell size of $3 \mathrm{~mm}$ and a strut diameter of $0.8 \mathrm{~mm}$ like in the reference article [17] were subjected to FEA using the initial mesh element types and sizes. In accordance with the scope of this study, the reaction forces in the elastic region were extracted with the aforementioned reaction force probe and compared with the results of the reference article [17]. While the reaction force values shown by the experimental results in the reference article [17] at the deformation levels of $0.4 \mathrm{~mm}, 0.6 \mathrm{~mm}, 0.8 \mathrm{~mm}, 1.2 \mathrm{~mm}, 1.6 \mathrm{~mm}$ and $2.0 \mathrm{~mm}$ were approximately $19500 \mathrm{~N}, 39000 \mathrm{~N}$, $48000 \mathrm{~N}, 55000 \mathrm{~N}$ and $60000 \mathrm{~N}$, they are $18622 \mathrm{~N}, 38847 \mathrm{~N}, 49030 \mathrm{~N}, 56078 \mathrm{~N}$ and $61300 \mathrm{~N}$ according to FEA simulation results. As the comparisons indicated a convergence which is better than $5 \%$, it has been evaluated that further mesh size alterations provide negligible improvements, and considering the computational costs, it is beneficial to stay within the initially determined gradient mesh element size ranges.

The last thing to highlight in terms of numerical modelling, was the calculation of relative elasticity modulus based on the FEA results. After reaction forces were obtained through the related probe which was implemented in FEA, the cumulative sum of those forces $\left(\sum F_{R}\right)$ was calculated and they were divided by the minimum areas $\left(A_{\min }\right)$ of each lattice structure configuration. By this way, the effective stresses $\left(\sigma_{e f f}\right)$ were derived (see Equation 4). Effective strains $\left(\varepsilon_{e f f}\right)$ on the lattice structures were also derived through dividing each deformation increment $(\Delta H)$ by the initial lattice structure height $\left(H_{0}\right)$ (see Equation 5). Final calculation was performed to reach elasticity modulus of lattice structures $\left(E_{L S}\right)$ via dividing the effective stresses by effective strains (see Equation 6).

$$
\begin{aligned}
& \sigma_{e f f}=\sum F_{R} / A_{\text {min }} \\
& \varepsilon_{e f f}=\Delta H / H_{0} \\
& E_{L S}=\sigma_{e f f} / \varepsilon_{e f f}
\end{aligned}
$$

\section{RESULTS AND DISCUSSIONS}

Figure 3 shows lattice volume fractions for different type of lattice structures depending on the cell size and strut diameter. As can be seen from Figure 3, for all lattice structure types, volume fraction increases with the increasing diameter and decreases with the increasing cell size. It is also obvious that with the utilization of same strut diameter and cell size (for example $\mathrm{d}=1 \mathrm{~mm}$ and $\mathrm{a}=3 \mathrm{~mm}$ ) FCC type lattice structure exhibits the highest volumetric fill while SC type lattice structures exhibit the lowest. Still, same volume fraction can be utilized for different lattice structure types by altering their dimensions. For example, an approximate 
volume fraction ratio of $10 \%$ can be achieved with a SC type lattice of $\mathrm{d}=1 \mathrm{~mm}$ and $\mathrm{a}=5 \mathrm{~mm}$ while the same ratio is also possible with a $\mathrm{BCC}$ type lattice of $d=0.8 \mathrm{~mm}$ and $\mathrm{a}=5 \mathrm{~mm}$.

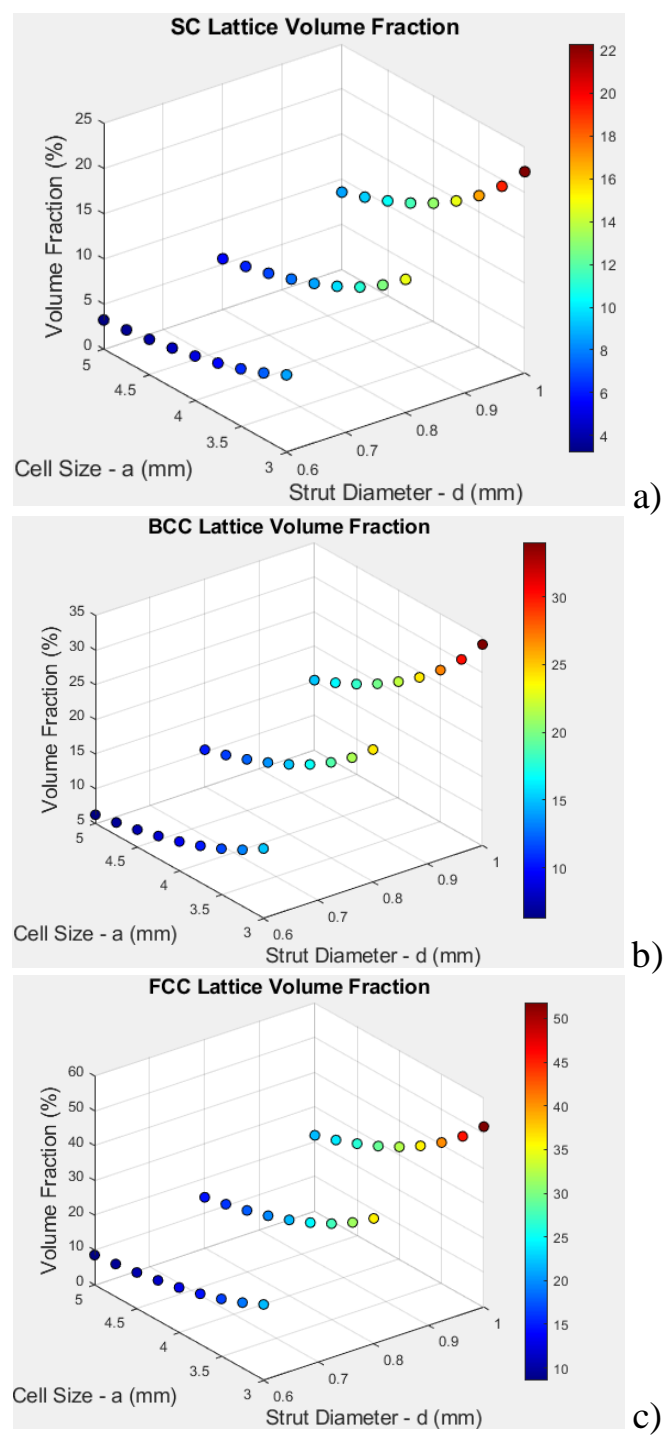

Figure 3. Lattice structure volume fractions for; a) SC type, b) BCC type, c) FCC type.

As for the elastic properties, FEA simulation results gave clear indications when considering deformations and forces which arose due to displacement of the upper prismatic body towards compression. Result plots were smooth and no singularities or peaks were observed (see Figure 4).

The results obtained in the presented research were compared with previously reported studies in the literature. For this comparison, attention was paid to the similarity of the lattice structure type, as well as the structure dimensions or volume fraction, between the current study and previous studies. In addition to these, care was taken so that the test method in the experimental studies, which was adopted as a reference for comparison, was similar to the compression method that was analyzed numerically in this study. This is because the test method has a major impact on the elastic modulus results, even if the same material, same lattice type, same cell size and same strut diameter are used. In a study conducted by Jiang et al. [22], it was seen that while compression and tensile tests gave similar results to each other, flexural tests revealed 6 times higher elasticity modulus for FCC type lattice structures. Another important aspect while comparing numerical analyzes and test results, especially for geometries as small as lattice structures, is that the use of nominal design and the actual geometry will cause significant changes in mechanical responses.

Carraturo et al. [12], examined this type of situation by performing numerical analyzes on nominal geometry and as-built geometry with manufacturing tolerance, and show that structures with the same material exhibit two different reaction forces as $1000 \mathrm{~N}$ and $2500 \mathrm{~N}$, due to compressive loading. In the assessment performed by considering the aforementioned aspects, the SC cubic structure was evaluated first and compared with the experimental data published by Hajnyš et al. [23], and the elastic modulus, which was experimentally reported as $9.01 \mathrm{GPa}$, was found to be $9.8 \mathrm{GPa}$ in the configuration having similar volume fraction ratio. Afterwards, an additional comparison was made for BCC type lattice structures and in the study published by Yasa et al. [19], the reported $21 \mathrm{GPa}$ value for samples produced from 316L material in the $\mathrm{XZ}$ direction was found to be $22.6 \mathrm{GPa}$ in the analyzes performed for BCC structures with similar volume fraction.

Finally, for FCC type lattice structures, a comparison was made with the publication of Köhnen et al. [24], which reported the test results as $11 \mathrm{GPa}$. In this publication, $12.3 \mathrm{GPa}$ elastic modulus was obtained for FCC lattice structures with similar volume fraction ratio. It is interesting to see that all the values obtained as the result of the numerical analyzes in this study were approximately $10 \%$ higher than the experimental test results with which they were compared. Although it is not possible to fully explain the reason for this situation due to the fact that the experimental results are taken from the literature, it is interpreted that the nominal 
geometries used in numerical analyzes without any defects can exhibit higher mechanical attributes than the actual samples produced with some defects such as surface roughness or undesired porosities.

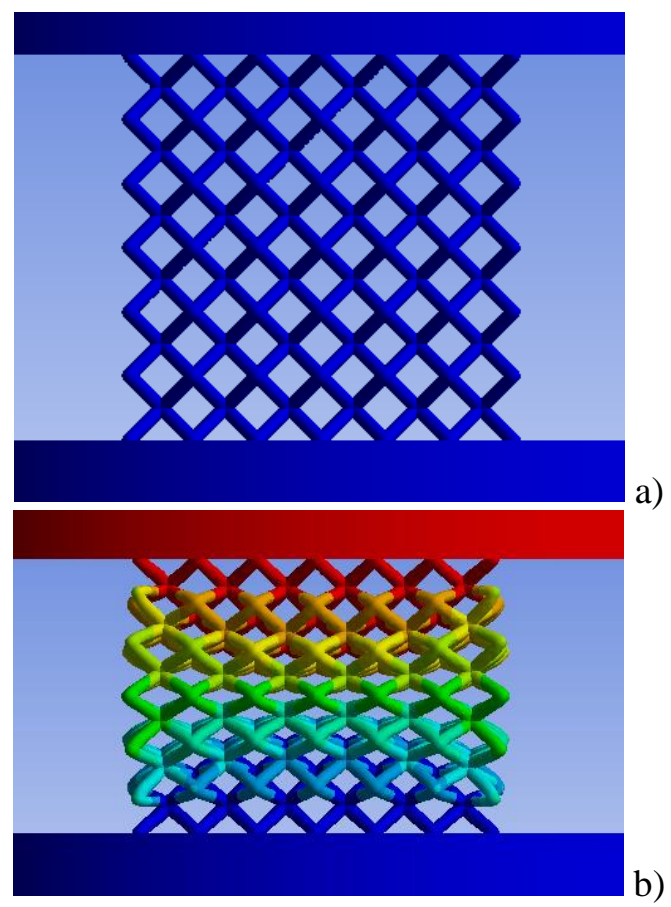

Figure 4. FEA result plots for BCC type lattice structure; a) Initial condition, b) Intermediate deformation $(6 \mathrm{~mm})$ condition.

After obtaining the results and calculating the elastic modulus as described in the materials and methods section, it could be stated that elastic modulus is highly dependent on the lattice structure type and volume fraction. Figure 5 shows the relative elastic modulus and its dependence on the volume fraction. In the figure, blue, green and red colors correspond to different lattice structure types of BCC, FCC and SC. The different markers of circle, square and triangle indicates the cell sizes of $3 \mathrm{~mm}$, $4 \mathrm{~mm}$ and $5 \mathrm{~mm}$. These attributes can also be observed through the legend. Furthermore, each series show 3 levels of strut diameters as $\mathrm{d} 0.6 \mathrm{~mm}, \mathrm{~d} 0.8 \mathrm{~mm}$ and $\mathrm{d} 1.0 \mathrm{~mm}$.

Similar to the previous studies in the literature, it is visible that the increase in the volume fraction increases the relative elastic modulus [9]-[19]. For all lattice structure types, this increase is much pronounced for the configurations which have $3 \mathrm{~mm}$ cell sizes (BCC-a3, FCC-a3, SC-a3). This increase is also correlated with increasing strut diameter from $\mathrm{d} 0.6 \mathrm{~mm}$ to $\mathrm{d} 1.0 \mathrm{~mm}$ for each series. The reason for this can be interpreted as a nearly 2 -fold rise in volumetric occupancy with the increase in strut diameters of the lattices, which are already more congested due to the smaller $3 \mathrm{~mm}$ cell size.

Another important aspect worth to emphasize is the relative elastic modulus difference between BCC, FCC and SC lattices. In this respect, SC lattices represent the highest relative elastic modulus while FCC lattices indicate the lowest. To explain this situation with an example, it will be necessary to look at the points that provide a relative elastic modulus of 0.18 for lattices with a cell size of $3 \mathrm{~mm}$ (a3) and their intersection with the horizontal axis, which shows the volume fraction (see Figure 5). As a result of this examination, it can be seen that among lattice structures with a cell size of $3 \mathrm{~mm}$ and a relative elastic modulus of 0.18 , the volume fraction of BCC is about 0.35 , FCC is about 0.45 , and SC is about 0.25 . When the studies in the literature are reviewed, it is understood that similar trends have been reached [4].

Apart from the previous experimental and numerical studies, it would also be beneficial to benchmark the findings with previous analytical models. The analytical models, first introduced by Gibson and Ashby and later developed by the same group of researchers, is one of the most referenced models in the literature, with its correlation between the volume fraction of porous structures and their material properties. These models examine porous structures in two main groups as bending-dominated and stretchdominated [25]. While the ratio of elasticity modulus of lattice structures $\left(E_{L S}\right)$ to elasticity modulus of solid material $\left(E_{L S}\right)$ is proportional to the square of the density $(\rho)$ or volume fraction for bending-dominated structures (Equation 7), it is directly proportional to the volume fraction in stretch-dominated counterparts (Equation 8).

$$
\begin{aligned}
& E_{L S} /_{E_{S}}=C\left(\rho^{\rho_{L S}} / \rho_{S}\right)^{2} \\
& E_{L S}{/ E_{S}}=C\left({ }^{\rho_{L S}} / \rho_{S}\right)
\end{aligned}
$$

In this publication, calculations have been made according to the relevant analytical models [25] and the results are included in Figure 5. In the figure, continuous black lines correspond to bending-dominated behavior and dashed black 
lines correspond to stretch-dominated behavior. As can be seen from Figure 5, the only type of lattice structure that exhibits a closer stance to stretch-dominated behavior is the SC lattice structure. This result is consistent with the previous literature [26]. But it should be noted that, this behavior is only valid for compressive loading, which is the case for this study. Another obvious result seen in Figure 5 is that FCC type lattice structures tends to display bending-dominated behavior. This is also in line with what has been reported in the previous literature [27]

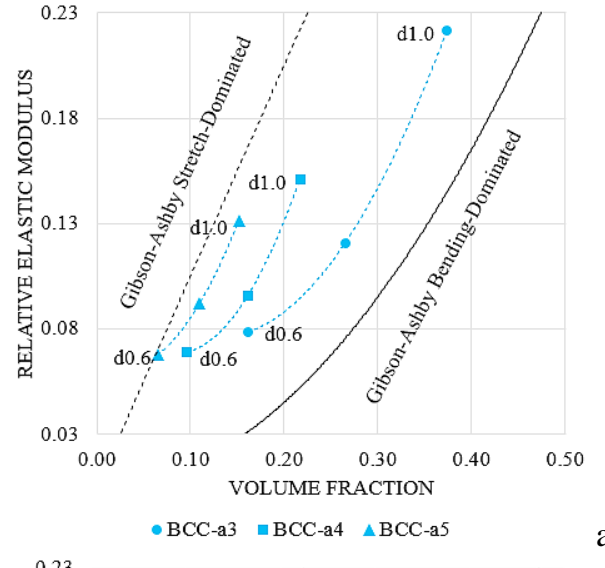

a)
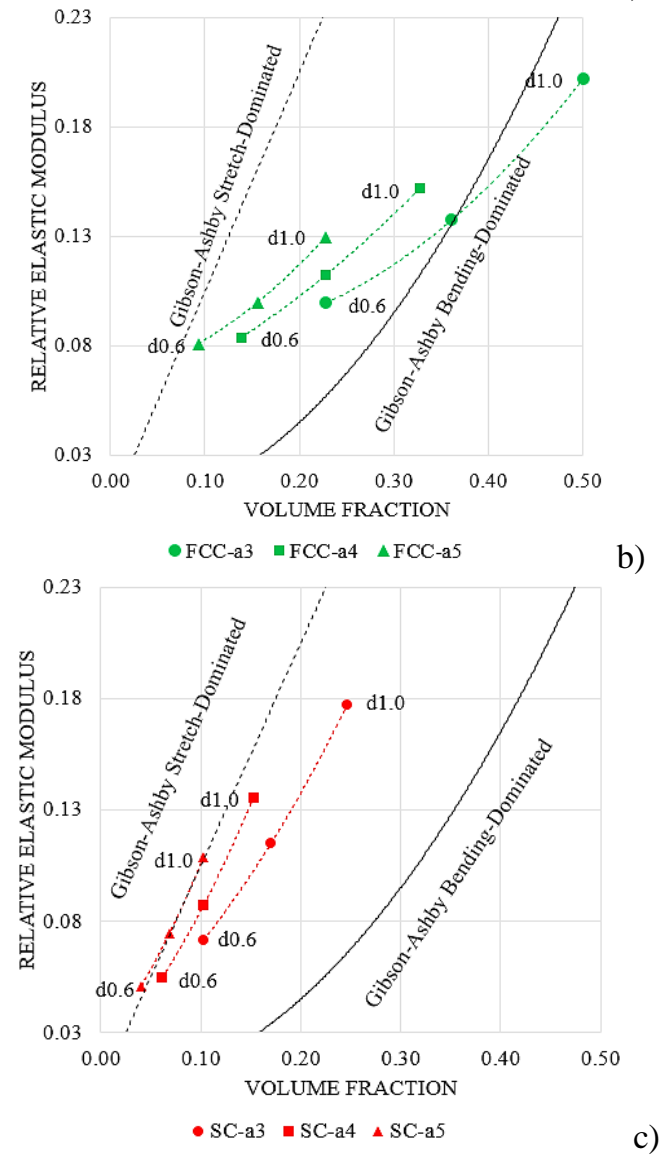

Figure 5. Relative elasticity modulus and volume fraction of; a) BCC, b) FCC and c) SC lattice structures.

\section{CONCLUSIONS}

This paper investigates the physical and elastic properties of lattice structures produced by SLM from 316L stainless steel material. 27 combinations of 3 different lattice structures (BCC, FCC and SC), 3 different cell sizes and 3 different diameters, were examined. Analytical and numerical calculation methods were performed in order to identify physical and elastic properties. The calculations have been verified by the experimental studies in the previous literature and an acceptable level of convergence has been achieved. The results of the benchmarks can be summarized as follows:

- For all lattice structure types, volume fraction increases with the increasing diameter and decreases with the increasing cell size.

- With the utilization of same strut diameter and cell size FCC type lattice structures exhibit the highest volumetric fill while SC type lattice structures exhibit the lowest.

- It could be stated that elastic modulus is highly dependent on the lattice structure type and volume fraction.

- The increase in the volume fraction increases the relative elastic modulus. This increase is much pronounced for the configurations which have smaller cell sizes.

- For the same volume fraction, SC lattices represent the highest relative elastic modulus while FCC lattices indicate the lowest.

- SC lattice structures exhibit a closer stance to stretch-dominated behavior and FCC type lattice structures tends to display bending-dominated behavior under compressive loading.

\section{ACKNOWLEDGES}

This work, which is the part of a project named "Parametric Investigation of Lattice Structures Used in Additive Manufacturing" was supported by Eskişehir Technical University (ESTÜ) - Grant No: 21LTP028.

\section{REFERENCES}

1. Poyraz, Ö., Kuşhan, M.C., "Investigation of the effect of different process parameters for laser additive manufacturing of metals", Journal of the Faculty of Engineering and Architecture of Gazi University, Vol. 33, Issue 2, Page 729-742, 2018. 
2. Kuşhan, M. C., Poyraz, Ö., Uzunonat, Y., Orak, S., "Systematical Review On The Numerical Simulations Of Laser Powder Bed Additive Manufacturing”, Sigma: Journal of Engineering \& Natural Sciences/Mühendislik ve Fen Bilimleri Dergisi, Vol. 36, Issue 4, Page 1197-1214, 2018.

3. Poyraz, Ö., Bilici, B.E., Gedik, Ş.C., "Hücresel Kafes Yapılarının Eklemeli İmalatı: Tasarım Karakteristikleri, Üretim Ve Performansı", Selçuk 4. Uygulamalı Bilimler Kongresi, Karaman, Sayfa 1423, Konya, 2021.

4. Hanks, B., Berthel, J., Frecker, M., Simpson, T. W., "Mechanical properties of additively manufactured metal lattice structures: data review and design interface", Additive Manufacturing, Vol.35, Issue 101301, Page 1-14, 2020.

5. Vafadar, A., Guzzomi, F., Rassau, A., Hayward, K., "Advances in metal additive manufacturing: a review of common processes, industrial applications, and current challenges", Applied Sciences, Vol. 11, Issue 3, Page 1-31, 2021.

6. Gürkan, D., Sağbaş, B. “Additively Manufactured Ti6al4v Lattice Structures for Biomedical Applications", International Journal Of 3d Printing Technologies And Digital Industry, Vol. 5, Issue 2, Page 155-163, 2021.

7. Kayacan, M. C., Baykal, Y. B., Karaaslan, T., Özsoy, K., Alaca, İ., Duman, B., Delikanlı, Y. E., "Monitoring the osseointegration process in porous Ti6Al4V implants produced by additive manufacturing: an experimental study in sheep", Journal of Applied Biomaterials \& Functional Materials, Vol. 16, Issue 2, Page 68-75, 2018.

8. Bajaj, P., Hariharan, A., Kini, A., Kürnsteiner, P., Raabe, D., Jägle, E. A., "Steels in additive manufacturing: A review of their microstructure and properties", Materials Science and Engineering: A, Vol. 772, Issue 138633, Page 1-25, 2020.

9. Alsalla, H., Hao, L., Smith, C., "Fracture toughness and tensile strength of $316 \mathrm{~L}$ stainless steel cellular lattice structures manufactured using the selective laser melting technique", Materials Science and Engineering: A, Vol. 669, Page 1-6, 2016.

10. Ashouri, D., Voshage, M., Burkamp, K., Kunz, J., Bezold, A., Schleifenbaum, J. H., Broeckmann, C., "Mechanical behaviour of additive manufactured 316L f2ccz lattice structure under static and cyclic loading”, International Journal of Fatigue, Vol. 134, Issue 105503, 2020.

11. Britt, C., Montgomery, C. J., Brand, M. J., Liu, Z. K., Carpenter, J. S., Beese, A. M., "Effect of processing parameters and strut dimensions on the microstructures and hardness of stainless steel $316 \mathrm{~L}$ lattice-emulating structures made by powder bed fusion", Additive Manufacturing, Vol. 40, Issue 101943, Page 1-12, 2021.

12. Carraturo, M., Alaimo, G., Marconi, S., Negrello, E., Sgambitterra, E., Maletta, C., Auricchio, F, "Experimental and Numerical Evaluation of Mechanical Properties of 3D-Printed Stainless Steel 316L Lattice Structures", Journal of Materials Engineering and Performance, Vol. 30, Page 5247-5251, 2021.

13. Gümrük, R., Mines, R. A. W., Karadeniz, S., "Static mechanical behaviours of stainless-steel micro-lattice structures under different loading conditions", Materials Science and Engineering: A, Vol. 586, Page 392-406, 2013.

14. Ushijima, K., Cantwell, W. J., Chen, D. H., "Prediction of the mechanical properties of microlattice structures subjected to multi-axial loading", International Journal of Mechanical Sciences, Vol. 68, Page 47-55, 2013.

15. Isaenkova, M. G., Yudin, A. V., Rubanov, A. E., Osintsev, A. V., Degadnikova, L. A., "Deformation behavior modelling of lattice structures manufactured by a selective laser melting of $316 \mathrm{~L}$ steel powder", Journal of Materials Research and Technology, Vol. 9, Issue 6, Page 15177-15184, 2020.

16. McKown, S. S. S. S., Shen, Y., Brookes, W. K., Sutcliffe, C. J., Cantwell, W. J., Langdon, G. S., Theobald, M. D., "The quasi-static and blast loading response of lattice structures", International Journal of Impact Engineering, Vol. 35, Issue 8, Page 795810,2008

17. Płatek, P., Sienkiewicz, J., Janiszewski, J., Jiang, F., "Investigations on mechanical properties of lattice structures with different values of relative density made from $316 \mathrm{~L}$ by selective laser melting (SLM)", Materials, Vol. 13, Issue 9, Page 1-26, 2020 .

18. Rosa, F., Manzoni, S., Casati, R., "Damping behavior of $316 \mathrm{~L}$ lattice structures produced by Selective Laser Melting", Materials \& Design, Vol. 160, Page 1010-1018, 2018.

19. Yasa, E., Ay, G. M., Türkseven, A. "Tribological and mechanical behavior of AISI $316 \mathrm{~L}$ latticesupported structures produced by laser powder bed fusion", The International Journal of Advanced Manufacturing Technology, Vol. 118, Page 17331748, 2022. 
20. Sienkiewicz, J., Płatek, P., Jiang, F., Sun, X., Rusinek, A., "Investigations on the mechanical response of gradient lattice structures manufactured via SLM”, Metals, Vol. 10, Issue 2, Page 1-19, 2020.

21. Liu, X., Wada, T., Suzuki, A., Takata, N., Kobashi, M., Kato, M., "Understanding and suppressing shear band formation in strut-based lattice structures manufactured by laser powder bed fusion", Materials \& Design, Vol. 199, Issue 109416, Page 1-13, 2021.

22. Jiang, C. P., Wibisono, A. T., Pasang, T., "Selective Laser Melting of Stainless Steel 316L with Face-Centered-Cubic-Based Lattice Structures to Produce Rib Implants", Materials, Vol. 14, Issue 20, Page 1-20, 2021.

23. Hajnyš, J., Pagáč, M., Zlámal, T., Petrů, J., Kousal, L., "Stiffness of 316L stainless steel support structures proposed for the SLM process", In MATEC Web of Conferences, Vol. 244, Page 01008, 2018.
24. Köhnen, P., Haase, C., Bueltmann, J., Ziegler, S., Schleifenbaum, J. H., Bleck, W. "Mechanical properties and deformation behavior of additively manufactured lattice structures of stainless steel", Materials \& Design, Vol. 145, Page 205-217, 2018.

25. Ashby, M. F., Evans, T., Fleck, N. A., Hutchinson, J. W., Wadley, H. N. G., Gibson, L. J., "Metal foams: a design guide", Elsevier, 2000.

26. Patil, G. U., Matlack, K. H., "Effective property evaluation and analysis of three-dimensional periodic lattices and composites through Blochwave homogenization", The Journal of the Acoustical Society of America, Vol. 145, Issue 3, Page 1259-1269, 2019.

27. Maconachie, T., Leary, M., Lozanovski, B., Zhang, X., Qian, M., Faruque, O., and Brandt, M, "SLM lattice structures: Properties, performance, applications and challenges", Materials \& Design, Vol. 183, 108137, Pages 1-18, 2019. 